\title{
Analysis and Design of a Novel Multiband Antenna for Mobile Terminals
}

\author{
Yuan Yao, ${ }^{1}$ Wanzhong Chen, ${ }^{1}$ Xiaodong Chen, ${ }^{1,2}$ and Junsheng Yu ${ }^{1}$ \\ ${ }^{1}$ School of Electronic Engineering, Beijing University of Posts and Telecommunications, Beijing 100876, China \\ ${ }^{2}$ School of Electronic Engineering and Computer Science, Queen Mary University of London, London E14NS, UK
}

Correspondence should be addressed to Yuan Yao; yaoy@bupt.edu.cn

Received 1 June 2015; Accepted 27 September 2015

Academic Editor: Mohammod Ali

Copyright (C) 2015 Yuan Yao et al. This is an open access article distributed under the Creative Commons Attribution License, which permits unrestricted use, distribution, and reproduction in any medium, provided the original work is properly cited.

A multiband planar terminal antenna with a compact size of $40 \mathrm{~mm} \times 24 \mathrm{~mm}$ is proposed in this paper. This antenna consists of a monopole patch with two slots on it and a meandering strip loaded on the top. Two parasitic stubs and a branch on the ground are used to adjust and widen the impedance bandwidth of the antenna. Simulations and measurements are carried out to study the antenna performances in terms of impedance matching, efficiency, gain, and radiation patterns. Both of simulation and measurement results are shown to illustrate the good performance of the proposed antenna. The antenna can operate at $450-$ $474 \mathrm{MHz}, 860-1040 \mathrm{MHz}, 1705-2428 \mathrm{MHz}$, and 2500-2710 MHz. These operating bandwidths cover GSM900, DCS, PCS, UMTS, LTE2500, and LTE's low frequency band (450-470 MHz). It is very suitable for multifunctional terminal applications in wireless communication systems.

\section{Introduction}

With the development of wireless communication technology, study and design of mobile terminal antennas are getting more and more attentions. Based on the wide range of mobile applications and variety of functions, more and more frequency bands are used to meet these requirements. The use of more frequency bands has driven the demand of antennas that can operate in multifrequency bands [1-3]. Since there is small volume available for antennas, the terminal antennas should have compactness characteristic [4-6].

Current mobile terminal antennas mainly use two types of antennas: planar inverted F-shaped antenna $[7,8]$ and planar monopole antenna [9-11]. To achieve multiband antenna in a limited area, antenna miniaturization becomes a vital issue. Slot antennas were used to achieve miniaturization [12, 13]. The sizes of antennas fabricated on substrates with high permittivity can also be reduced [14]. Besides, meandering strip was used to decrease the dimension of the antennas [15]. These miniaturization methods are very practical for mobile terminal antennas. However, the miniaturization requirements for multifunctional wireless communication systems are stricter, using only one of these methods to realize miniaturization is not enough. So we can choose combinations of several miniaturizations techniques.

Several methods have been proposed to achieve multiband characteristic. The main common method is using multiple branches, in which each branch resonate at one frequency, to realize multiple resonances [16-18]. Multislots technology was also used to realize multiband $[19,20]$. Besides multiband characteristic, the bandwidth of each resonant frequency should be widened because there may be multiprotocols in one wideband. Thus, several methods were proposed to extend the bandwidth of the antenna. Parasitic structures can generate additional resonant frequency near the main resonant band to merge into one wideband [21]. Stubs on ground can improve the impedance matching and widen the working bandwidth [22]. Most of the multiband antenna designs in the literatures cover the working band $800-2170 \mathrm{MHz}$, which is pretty enough for $2 \mathrm{G}$ and $3 \mathrm{G}$ mobile communication systems but is not for the $4 \mathrm{G}$ mobile communication systems. Since there are more than forty bands designated as LTE bands from several hundred $\mathrm{MHz}$ to several $\mathrm{GHz}$, the antenna in the terminals should accommodate as much frequency bands as possible. 


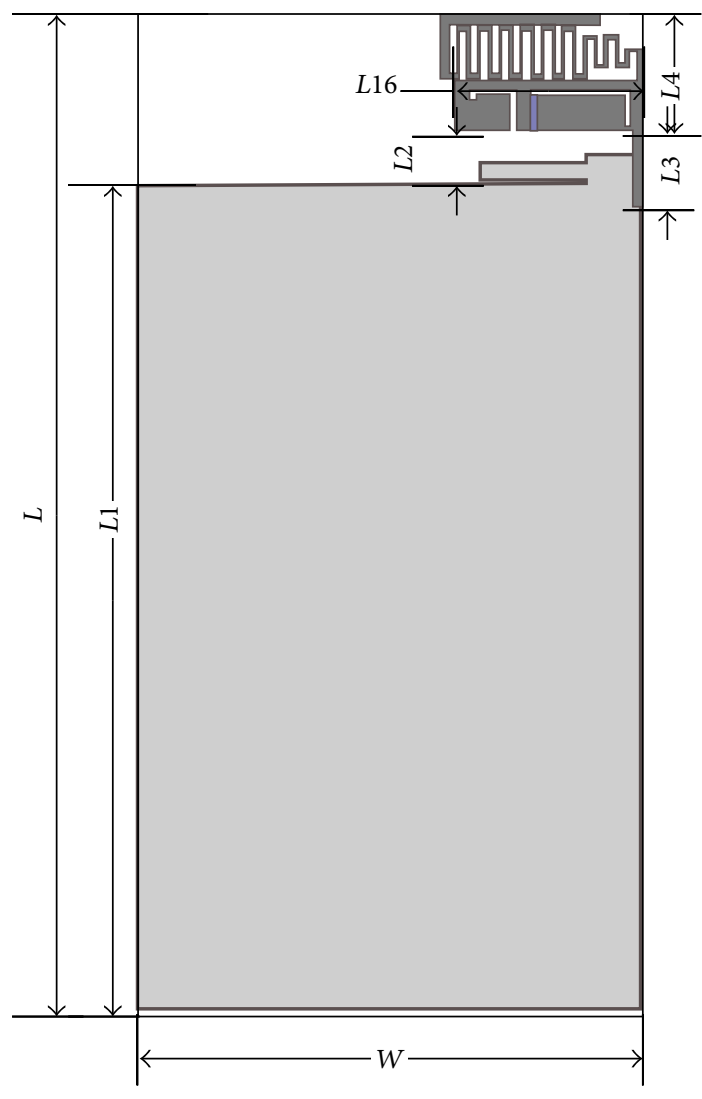

Figure 1: The overall view of the whole antenna.

This paper proposes a novel multiband antenna which covers many frequency bands including GSM900 (890$960 \mathrm{MHz})$, GSM1800 (1710-1880 MHz), GSM1900 (1850$1990 \mathrm{MHz})$, UMTS (1920-2170 MHz), LTE2500 (2500$2690 \mathrm{MHz})$, and LTE's low frequency band (450-470 MHz). The meandering strip, antenna slot, parasitic branches, and stub on the ground were used to achieve both of multiband and compactness characteristics. Parasitic branches and stub on the ground can also widen the working frequency bands. Simulation and measurement results are shown to illustrate the good performance of the antenna. The results showed that the performance of the proposed antenna is pretty good and it is suitable for mobile terminal applications.

\section{Antenna Design}

In this design, the proposed antenna is expected to work at $450-470 \mathrm{MHz}, 860-960 \mathrm{MHz}, 1710-2160 \mathrm{MHz}$, and $2500-$ $2690 \mathrm{MHz}$. The structure of the proposed antenna is shown in Figures 1, 2, and 3. Figure 1 shows the overall view of the whole antenna. Figure 2 shows the front face of the sectional antenna. Figure 3 shows the back face of the antenna. It consists of a planar monopole antenna with two slots on it and a meandering strip top loaded on the top layer, while a rectangular ground plane, a stub on ground, and two parasitic branches are etched on the bottom layer. The antenna is

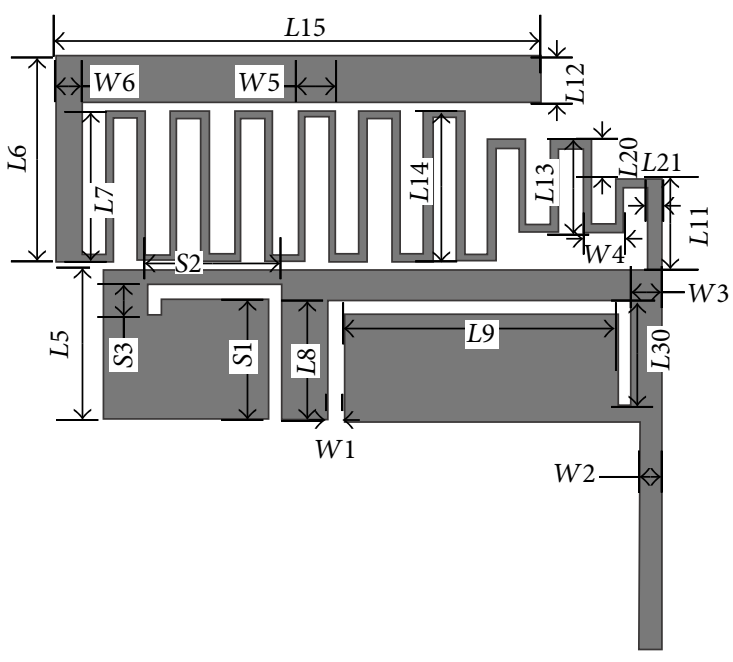

FIGURE 2: The front face of the sectional antenna.

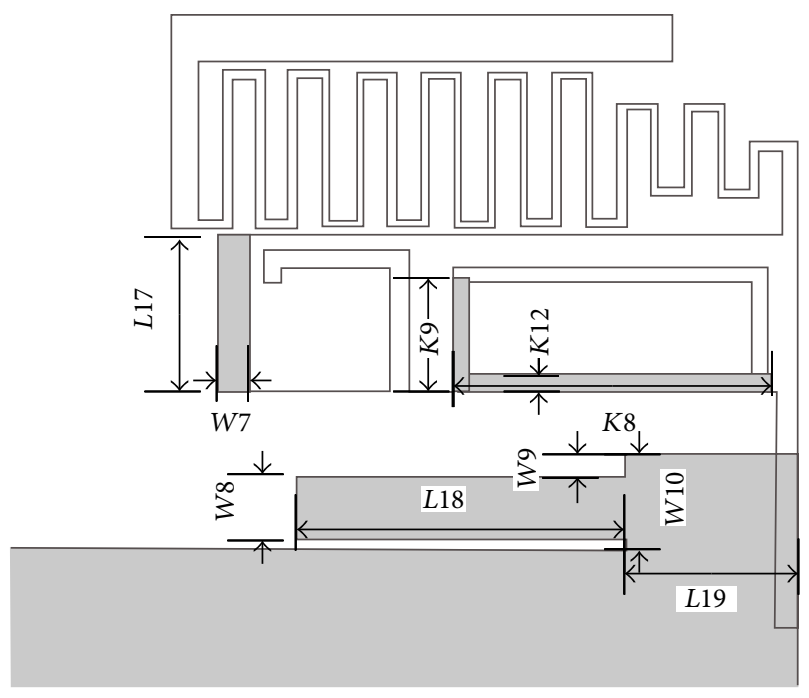

FIGURE 3: Back face of the antenna.

printed on a substrate with relative permittivity $\varepsilon_{r}=4.4$ and thickness $H=0.8 \mathrm{~mm}$.

In order to achieve multiband characteristic, slotted antenna technology is used without extra space. There are two slots on the monopole patch: $L$-form slot on the left (slot 1 ) and $L$-form slot on the right (slot 2). The monopole patch with two slots on it can generate three resonant frequencies. For LTE's low frequency band (450-470 MHz), a meandering line is loaded on the monopole patch. At the bottom of the substrate, there are a parasitic patch and a parasitic copper wire. The parasitic patch located at the left back of the monopole is used to adjust the operating bandwidth of slot 2. The parasitic copper wire broadens the operating frequency bandwidth of slot 2 at $2 \mathrm{GHz}$. The branch on the ground is used to improve the impedance matching of the proposed antenna, especially in the upper frequency band $2500-2690 \mathrm{MHz}$. 


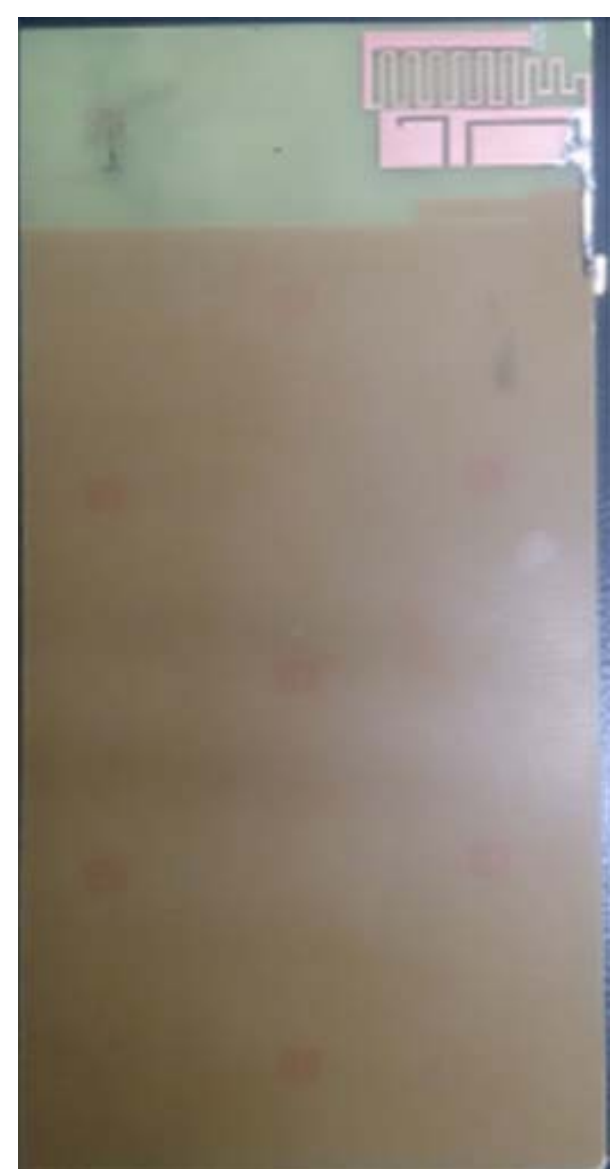

(a)

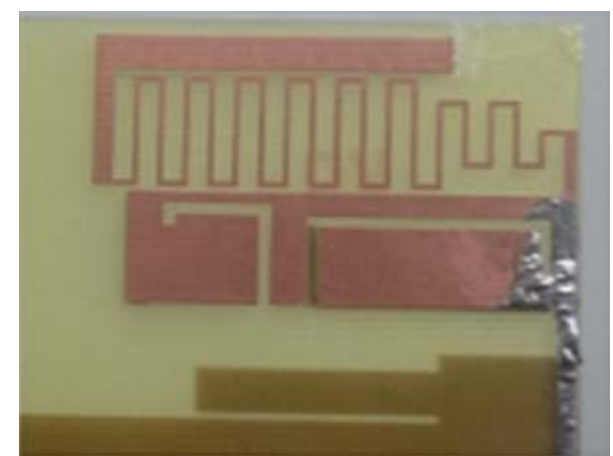

(b)

FIGURE 4: Photograph of the fabricated antenna: (a) overall antenna and (b) sectional antenna.

Figure 4 shows the fabricated antenna after parameter optimization. The antenna is fed by a SMA connecter with $50 \Omega$ impedance. The fed point is put at the right angle of patch. The finally chosen dimensions of the proposed antenna are illustrated in Table 1.

\section{Study of the Antenna}

3.1. Operating Mechanism. In order to describe the operating mechanism and the effect of the various portions of the antenna clearly, we have carried out the antenna design process step by step. Figure 5 shows the detailed design steps. Figures 6 and 7 show the values of $S_{11}$ when the structure of the antenna changes according to the steps in Figure 5.

From Figures 5, 6, and 7, we can see several features. The meandering line generates the lowest operating bandwidth $(450-470 \mathrm{MHz})$. The monopole patch generates the second bandwidth (860-960 MHz). The right slot (slot 2) generates the third bandwidth (1710-2160 MHz), while the left slot (slot 1) generates the fourth $(2500-2690 \mathrm{MHz})$. The branch on the ground extended and improved the impedance bandwidth of both slot 1 and slot 2 . The parasitic patch is used to adjust the bandwidths of slot 2, and parasitic copper wire is used to extend the bandwidth of slot 2 .
TABLE 1: Parameters of the proposed antenna (units: $\mathrm{mm}$ ).

\begin{tabular}{lccccccc}
\hline$L$ & $L 1$ & $L 2$ & $L 3$ & $L 4$ & $L 5$ & $L 6$ & $L 7$ \\
\hline 200 & 165 & 10 & 15 & 14 & 10 & 13.5 & 10 \\
\hline$L 8$ & $L 9$ & $L 11$ & $L 12$ & $L 13$ & $L 14$ & $L 15$ & $L 16$ \\
\hline 8 & 18 & 6 & 3 & 6 & 9.5 & 32 & 37 \\
\hline$L 17$ & $L 18$ & $L 19$ & $L 20$ & $L 21$ & $L 30$ & $S 1$ & $S 2$ \\
\hline 10 & 20 & 11 & 2.5 & 1 & 7 & 8 & 9 \\
\hline$S 3$ & $W$ & $W 1$ & $W 2$ & $W 3$ & $W 4$ & $W 5$ & $W 6$ \\
\hline 2 & 100 & 1 & 1.5 & 2 & 2.6 & 2.5 & 1.7 \\
\hline$W 7$ & $W 8$ & $W 9$ & $W 10$ & $W 11$ & $K 8$ & $K 9$ & $K 12$ \\
\hline 2 & 4 & 1.5 & 6 & 2 & 20 & 7.25 & 1 \\
\hline
\end{tabular}

To further prove the working principle, the current distributions of the proposed antenna at different working frequencies are shown in Figure 8. At $460 \mathrm{MHz}$, the current mainly located in the meandering strip. At $900 \mathrm{MHz}$, the current mainly located at the monopole and the meandering strip. At $2000 \mathrm{MHz}$, the current mainly located in the right slot 2, while, at $2600 \mathrm{MHz}$, the current mainly located at the left slot 1 . 


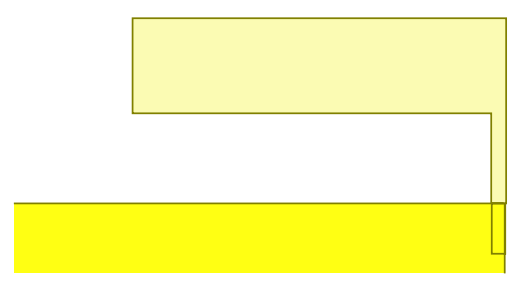

(a)

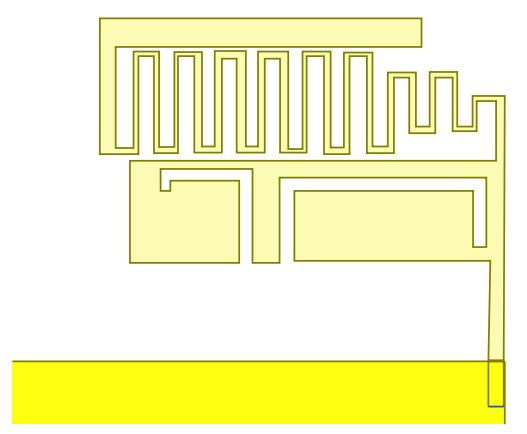

(d)

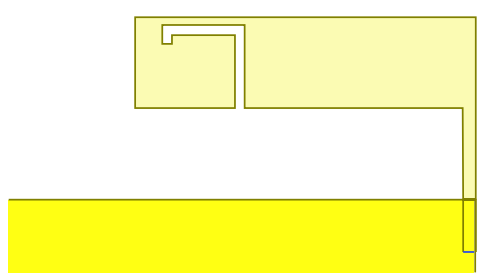

(b)

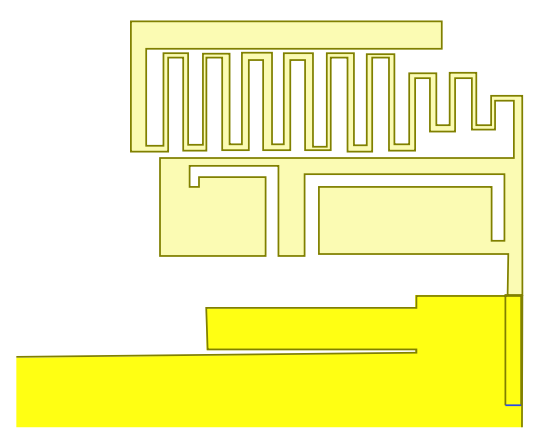

(e)

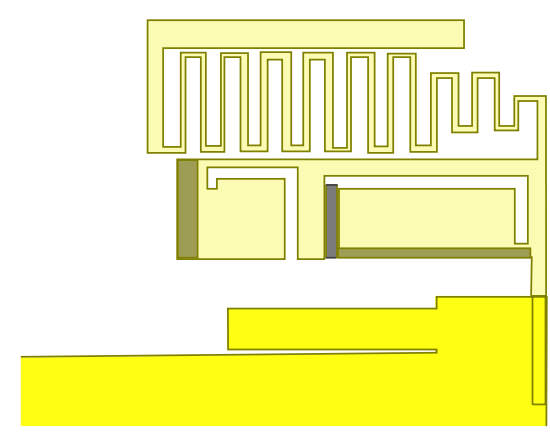

(g)

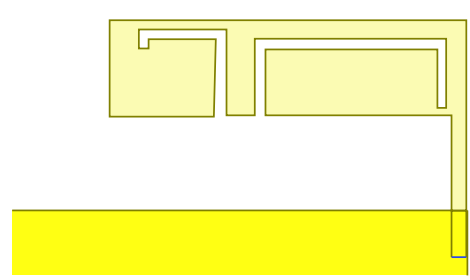

(c)

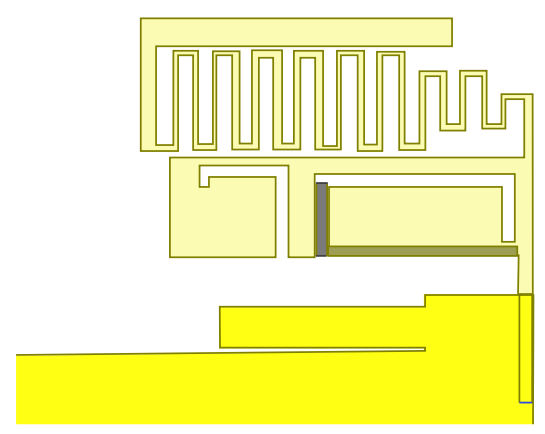

(f)

e; (b) with left slot; (c) with right slot; (d) with meandering strip; (e) FIGURE 5: Simulation flows of the designed antenna: (a) the monopole; (b)
with ground branch; (f) with parasitic copper wire; (g) with parasitic patch.

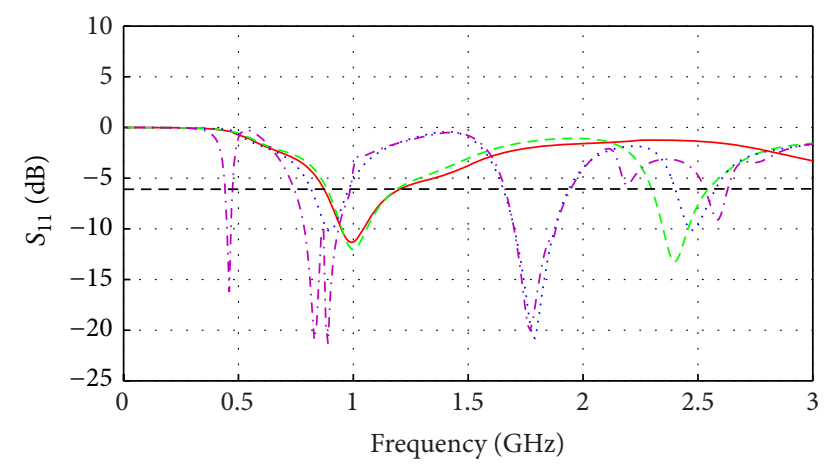

$-(\mathrm{a})$

(b) (c)

-.. (d)

Figure 6: Simulated $S_{11}$ of the structures (a), (b), (c), and (d) in Figure 5 .

\subsection{Parameter Study}

3.2.1. Monopole Patch Design (Main Parameter: L16). In this design, the monopole patch is expected to work at 876$960 \mathrm{GHz}$. According to (1), the wavelength of $900 \mathrm{MHz}$ in
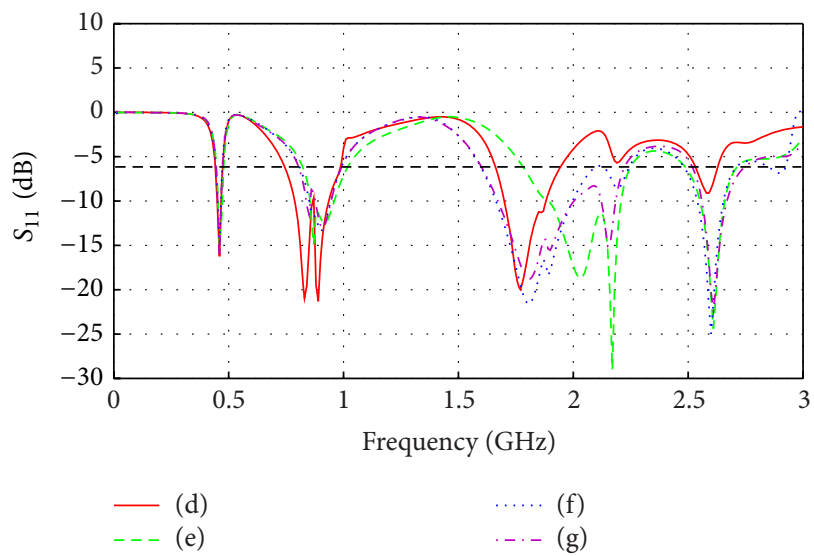

Figure 7: Simulated $S_{11}$ of the structures (d), (e), (f), and (g) in Figure 5.

FR-4 substrate is approximately $160 \mathrm{~mm}$. Since the length of monopole should be a quarter of the wavelength, we choose $40 \mathrm{~mm}$ as the initial length of the monopole patch. 


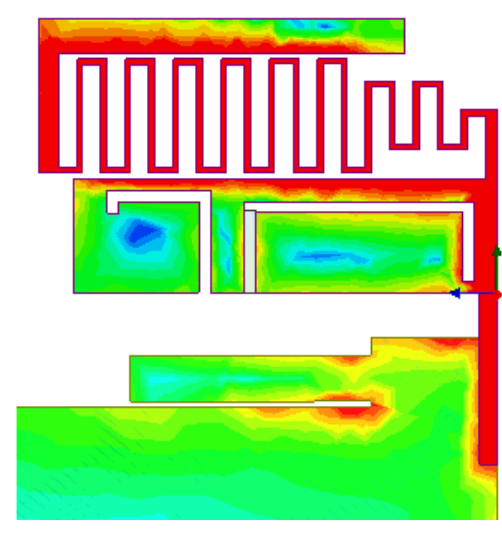

(a)

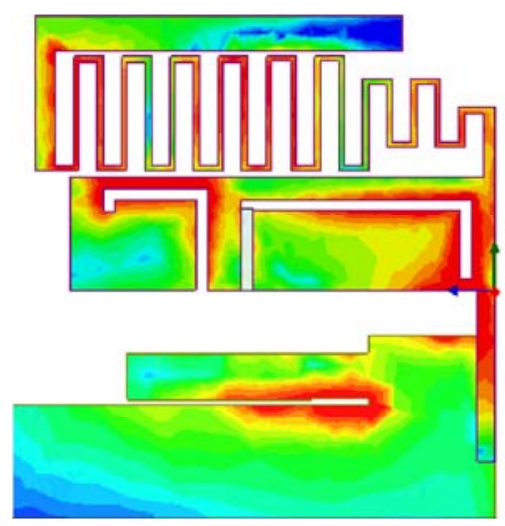

(c)

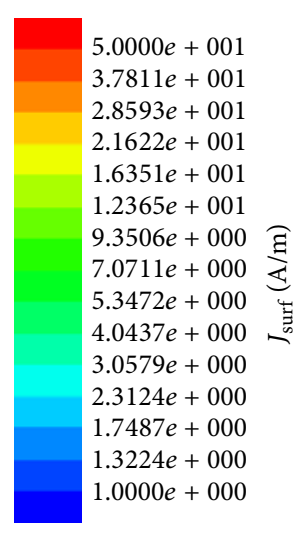

$5.0000 e+001$ $3.7811 e+001$ $2.8593 e+001$ $2.1622 e+001$ $1.6351 e+001$ $1.2365 e+001$ $9.3506 e+000$ $7.0711 e+000$ $5.3472 e+000$ $4.0437 e+000$ $3.0579 e+000$ $2.3124 e+000$ $1.7487 e+000$ $1.3224 e+000$ $1.0000 e+000$
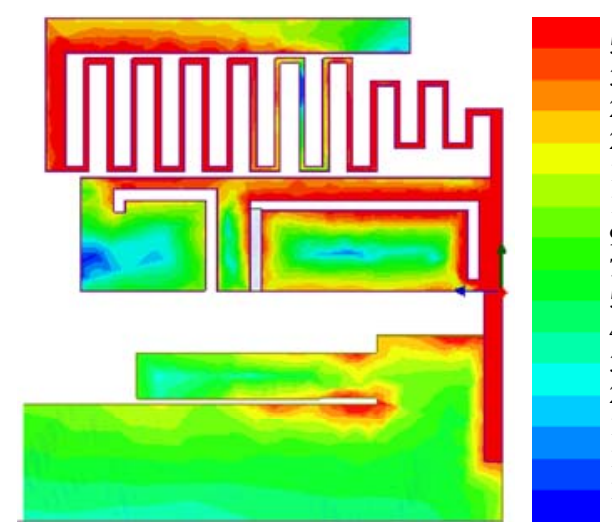

$5.0000 e+001$ $3.7811 e+001$ $2.8593 e+001$ $2.1622 e+001$ $1.6351 e+001$ $1.2365 e+001$ $9.3506 e+000$ $7.0711 e+000$ $5.3472 e+000$ $4.0437 e+000$ $3.0579 e+000$ $2.3124 e+000$ $1.7487 e+000$ $1.3224 e+000$ $1.0000 e+000$

(b)
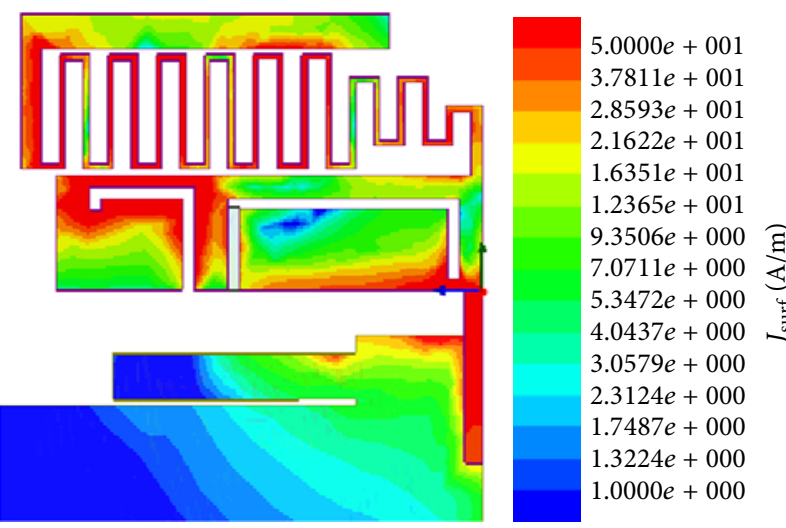

(d)

Figure 8: Simulated surface-current distributions of the proposed antenna at (a) $460 \mathrm{MHz}$; (b) $900 \mathrm{MHz}$; (c) $2000 \mathrm{MHz}$; (d) $2600 \mathrm{MHz}$.

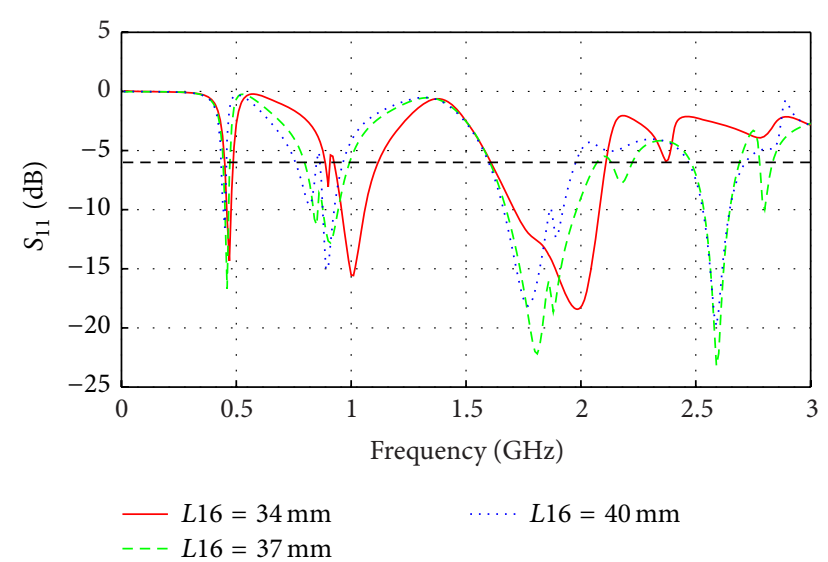

FIGURE 9: The optimization of length of monopole patch.

Simulations and optimizations were done to obtain the optimal structure. Figure 9 shows that the second operating band decreased as the increasing of $L 16$ and the optimal length of monopole is $37 \mathrm{~mm}$. Consider

$$
\lambda_{0}=\frac{c}{f \sqrt{\varepsilon_{r}}}
$$

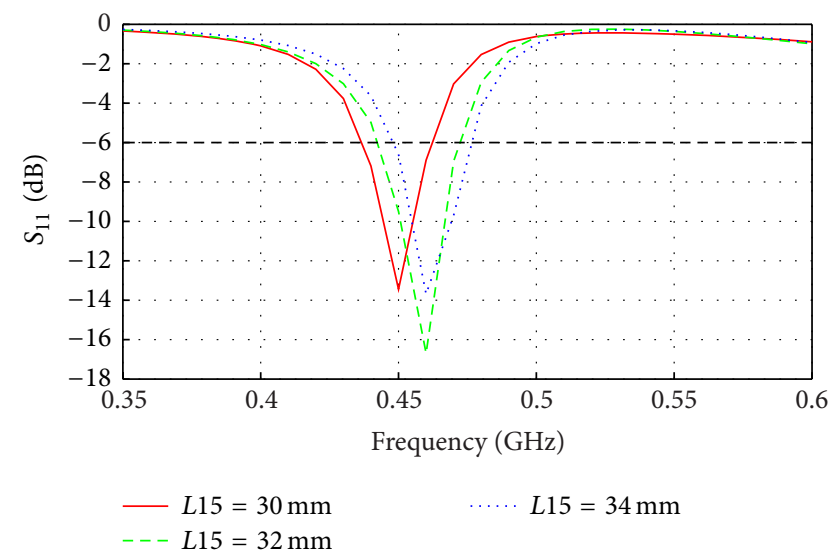

Figure 10: The optimization of meandered strip.

3.2.2. Meandering Strip Design (Main Parameter: L15). In order to cover $450-470 \mathrm{MHz}$, a meandering strip is used. It can maintain the compactness of the proposed antenna. Changing the length of the meandering strip (L15) can change the resonant frequency and the operating band. The optimization results are shown in Figure 10. It can be seen that the first working frequency band of the antenna decreases 


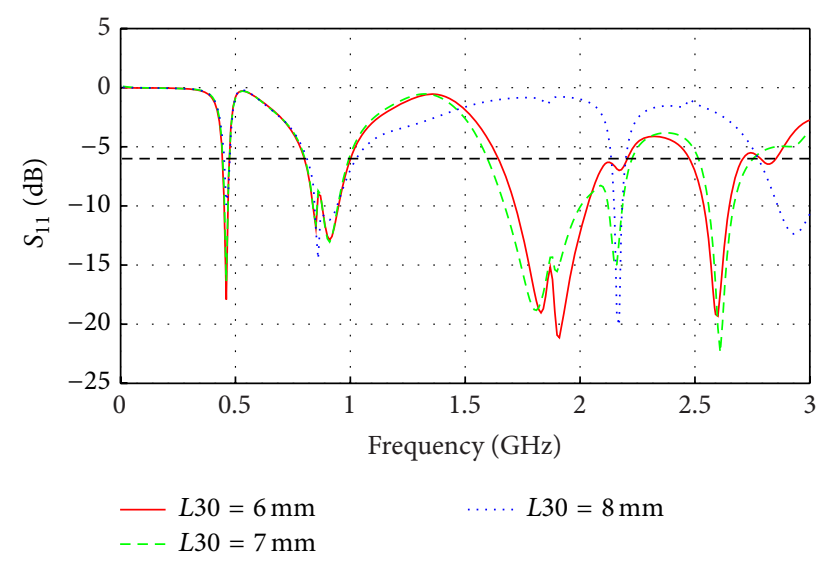

FIGURE 11: The optimization of $L$-form slot 2 .

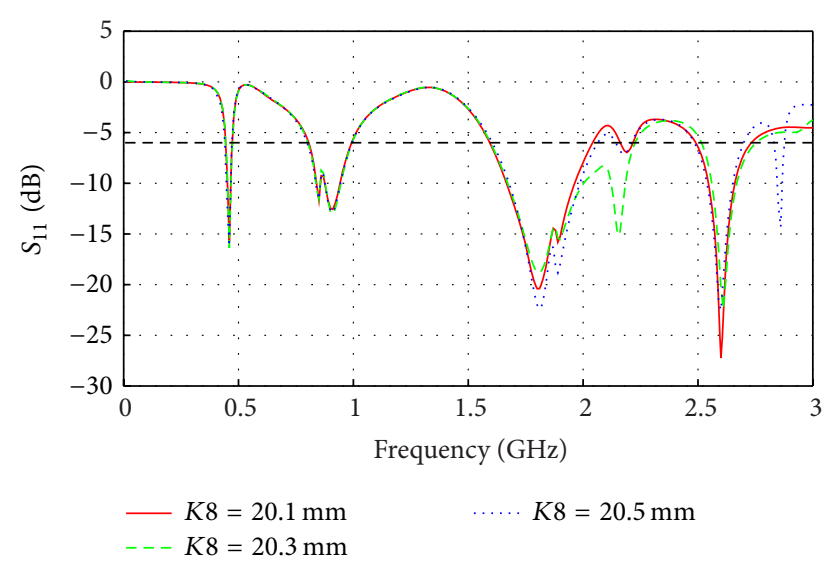

FIGURE 12: The optimization of parasitic copper wire.

with the increasing of $L 15$. The optimal length of $L 15$ is $32 \mathrm{~mm}$.

3.2.3. Slot 2 Design (Main Parameter: L30). In the proposed antenna design, we cut slots on the monopole patch to realize multiband characteristic without extra space. In the design, there are two slot antennas on the monopole patch: $L$-form slot 1 and $L$-form slot 2 . The width of all slots is $1 \mathrm{~mm}$. Figure 11 shows the optimization of $L$-form slot 2 . The value of L30 influences the third resonant frequency and the optimal length of $L 30$ is $7 \mathrm{~mm}$.

\subsubsection{Parasitic Parts and Ground Branch Design (Main} Parameter: $K 8, W 7$, and L18). In order to widen the operating frequency bands, two methods are adopted. First, a parasitic patch and a parasitic copper wire were used. Second, a ground branch is designed to improve the impedance matching. The branch on the ground extended and improved the impedance bandwidth of both slot 1 and slot 2 . The parasitic patch is used to adjust the bandwidths of slot 2, and parasitic copper wire is used to extend the bandwidth of slot 2 .

When the length of $K 8$ reaches $20.3 \mathrm{~mm}$ as shown in Figure 12, the operating band of $L$-form slot 2 meets the requirement and gets the best situation. The width of the

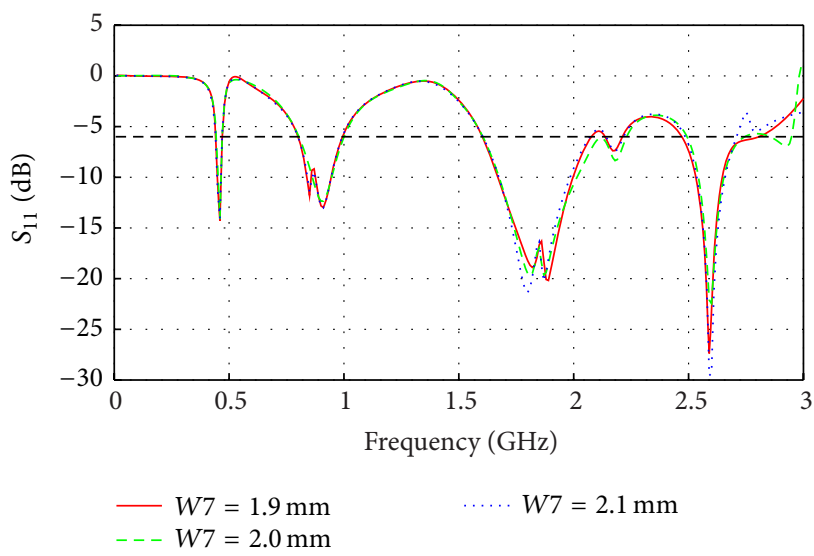

FIGURE 13: The optimization of parasitic patch.

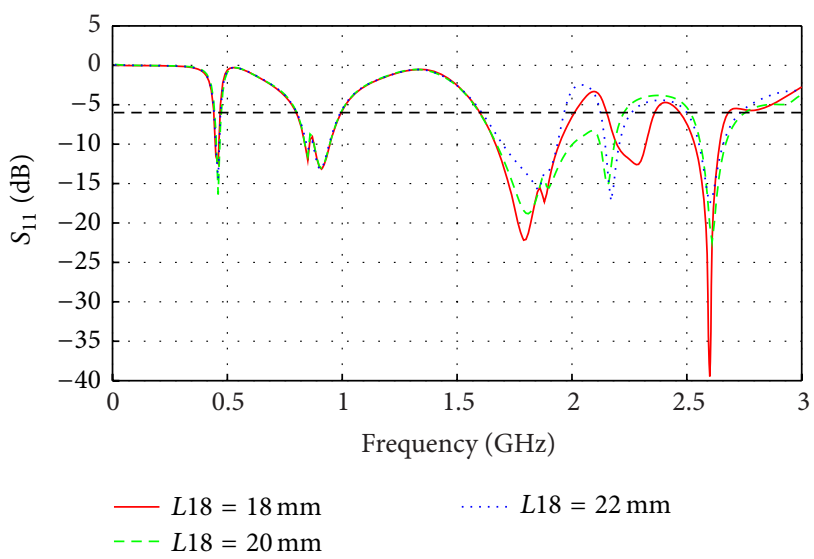

FIGURE 14: The optimization of ground branch.

parasitic patch (W7) adjusts the performance of slot 2 slightly as shown in Figure 13. Figure 14 shows the simulation of the ground branch. When the length the branch (L18) reaches three quarters of the main body of the antenna, the impedance bandwidth of slot 2 reaches the widest width.

\section{Results and Discussion}

Simulations and optimizations were performed using Ansoft HFSS software, while the measurements were carried out in a chamber.

4.1. S-Parameter. The simulated and measured $S_{11}$ are shown in Figure 15. There are little differences between both of them, and it is mainly due to manufacturing errors. In general, they agree quite well. The measured impedance bandwidths $\left(S_{11}<-6 \mathrm{~dB}\right)$ cover $450-474 \mathrm{MHz}, 860-$ $1040 \mathrm{MHz}, 1705-2428 \mathrm{MHz}$, and $2500-2710 \mathrm{MHz}$. This indicates that the antenna is suitable for mobile applications working at GSM900 (880-960 MHz), DCS (1710-1880 MHz), PCS (1850-1990 MHz), UMTS (1920-2170 MHz), LTE2500 (2500-2690 MHz), and LTE's low frequency band (450$470 \mathrm{MHz})$. 


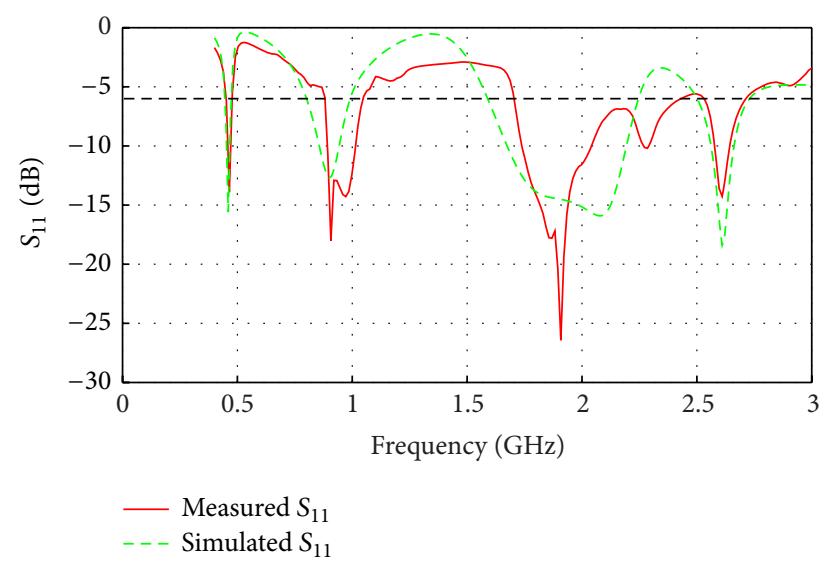

Figure 15: Simulated and measured $S_{11}$ of the proposed antenna.

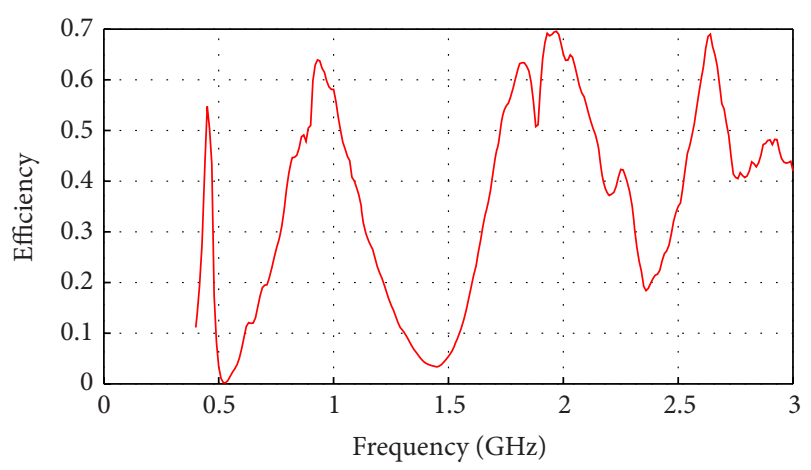

FIGURE 16: The measured efficiency of the proposed antenna.

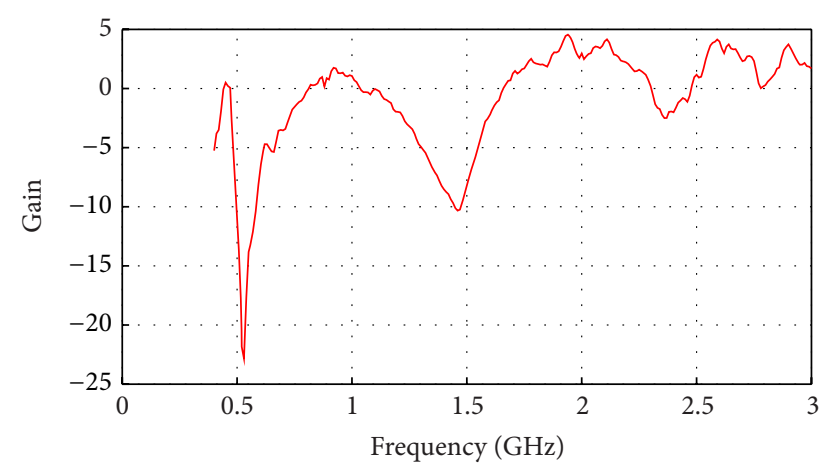

FIGURE 17: The measured gain of the proposed antenna.

4.2. Gain and Efficiency. The measured total efficiency and gain of the proposed antenna are shown in Figures 16 and 17. The measured efficiency is higher than $40 \%$ and the measured gain is higher than $0 \mathrm{dBi}$ in the frequency bands including 450-470 MHz, 820-1030 MHz, 1690-2170 MHz, and 2520$3000 \mathrm{MHz}$. These frequency bands cover our target bands.

4.3. Radiation Performance. The measured radiation patterns of the proposed antenna are shown in Figures 18, 19, 20, and 21 , respectively. It can be seen that the proposed antenna has omnidirectional radiation patterns at the working bands, which can meet the demands for mobile terminal antennas.

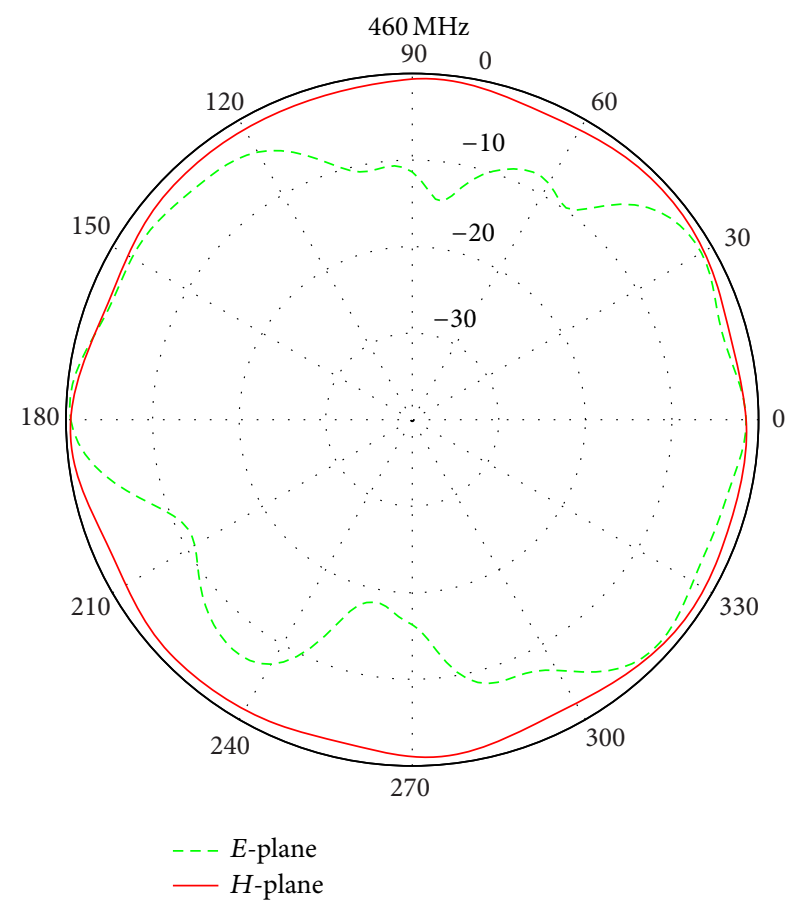

FIGURE 18: Measured radiation pattern of the proposed antenna at $460 \mathrm{MHz}$

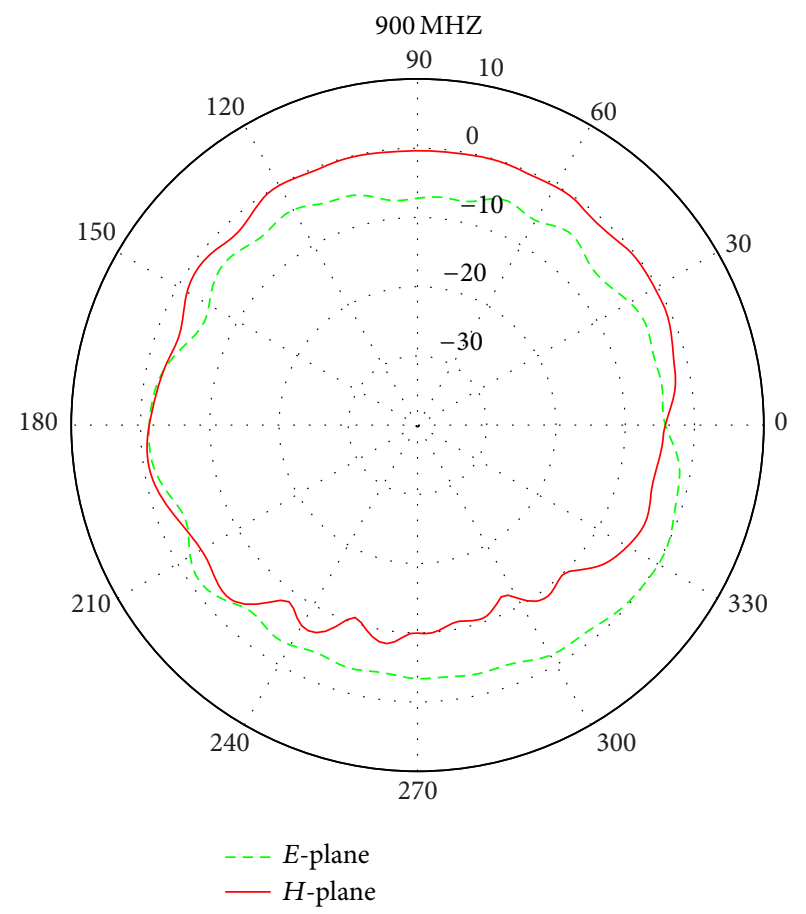

FIGURE 19: Measured radiation pattern of the proposed antenna at $900 \mathrm{MHz}$.

\section{Conclusion}

In this paper, a novel multiband antenna was proposed for mobile terminal applications. The proposed antenna consists 


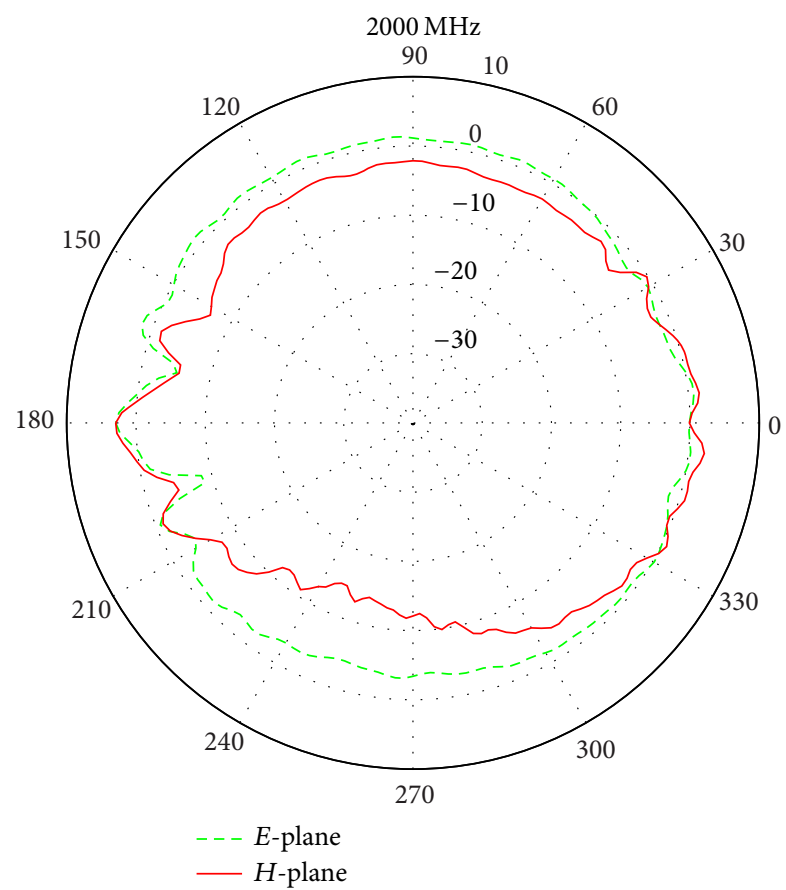

FIGURE 20: Measured radiation pattern of the proposed antenna at $2000 \mathrm{MHz}$.

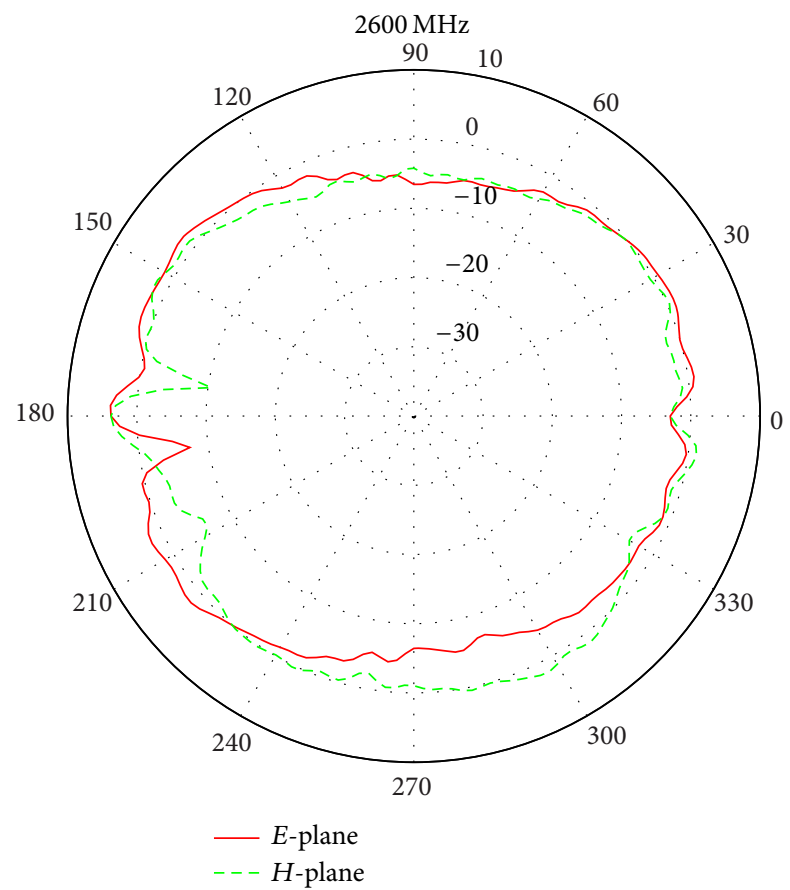

FIGURE 21: Measured radiation pattern of the proposed antenna at $2600 \mathrm{MHz}$.

of monopole patch with two slots on it, meandering line, parasitic patches, and the ground branch. The antenna can operate at $450-474 \mathrm{MHz}, 860-1040 \mathrm{MHz}, 1705-2428 \mathrm{MHz}$, and 2500-2710 MHz, which is over GSM900, DCS, PCS, UMTS, LTE2500, and LTE's low frequency band. The measurements show that it has good impedance matching. The measured efficiency is higher than $40 \%$ and the measured gain is higher than $0 \mathrm{dBi}$ within the whole operating frequency bands. It has omnidirectional radiation patterns. This proposed antenna is suitable for multifunctional terminals.

\section{Conflict of Interests}

The authors declare that there is no conflict of interests regarding the publication of this paper.

\section{Acknowledgments}

This work is supported by the National Natural Science Foundation of China under Grant no. 61201026 and Beijing Higher Education Young Elite Teacher Project (Grant no. YETP0438)

\section{References}

[1] Y. Hong, J. Tak, J. Baek, B. Myeong, and J. Choi, "Design of a multiband antenna for LTE/GSM/UMTS band operation," International Journal of Antennas and Propagation, vol. 2014, Article ID 548160, 9 pages, 2014

[2] C. G. Permana and A. Munir, "Printed multiband antenna for mobile and wireless communications," in Proceedings of the 6th International Conference on Telecommunication Systems, Services, and Applications (TSSA '11), pp. 236-240, IEEE, Bali, Indonesia, October 2011.

[3] Y. F. Cao, S. W. Cheung, and T. I. Yuk, "A multiband slot antenna for GPS/WiMAX/WLAN systems," IEEE Transactions on Antennas and Propagation, vol. 63, no. 3, pp. 952-958, 2015.

[4] L. Liu, S. W. Cheung, and T. I. Yuk, "Compact MIMO antenna for portable UWB applications with band-notched characteristic," IEEE Transactions on Antennas and Propagation, vol. 63, no. 5, pp. 1917-1924, 2015.

[5] Y. P. Wei, J. Chen, Y. C. Cao, and J. W. Man, "Printed small-size monopole antenna for LTE/WWAN smartphone application," in Proceedings of the 3rd Asia-Pacific Conference on Antennas and Propagation (APCAP '14), pp. 97-100, Harbin, China, July 2014.

[6] K. Y. Yazdandoost and R. Miura, "Compact printed multiband antenna for M2M applications," in Proceedings of the 8th European Conference on Antennas and Propagation (EuCAP '14), pp. 2521-2524, IEEE, The Hague, The Natherlands, April 2014.

[7] C.-T. Lee and K.-L. Wong, "Uniplanar printed coupled-fed PIFA with a band-notching slit for WLAN/WiMAX operation in the laptop computer," IEEE Transactions on Antennas and Propagation, vol. 57, no. 4, pp. 1252-1258, 2009.

[8] H. Park and J. H. Choi, "Design of broad quad-band planar inverted-F antenna for cellular/pcs/umts/dmb applications," Microwave and Optical Technology Letters, vol. 47, no. 5, pp. 415421, 2005.

[9] Y. Yao, R. Qiu, J. Yu, and X. Chen, "Design of a compact tri-band planar monopole antenna," in Proceedings of the International Conference on Microwave and Millimeter Wave Technology (ICMMT '12), pp. 1218-1221, Shenzhen, China, May 2012.

[10] Y. H. Cui, R. L. Li, and P. Wang, "A novel broadband planar antenna for 2G/3G/LTE base stations," IEEE Transactions on Antennas and Propagation, vol. 61, no. 5, pp. 2767-2774, 2013. 
[11] Z. N. Chen, D. X. Liu, and B. Gaucher, "A planar dualband antenna for $2.4 \mathrm{GHz}$ and UWB laptop applications," in Proceedings of the IEEE 63rd Vehicular Technology Conference (VTC '06), pp. 2652-2655, IEEE, Melbourne, Australia, May 2006.

[12] P. kumar Deb, T. Moyra, and P. Bhowmik, "Return loss and bandwidth enhancement of microstrip antenna using Defected Ground Structure (DGS)," in Proceedings of the 2nd International Conference on Signal Processing and Integrated Networks (SPIN '15), pp. 25-29, IEEE, Noida, India, Feburary 2015.

[13] A. A. Deshmukh and K. P. Ray, "Stub loaded multi-band slotted rectangular microstrip antennas," IET Microwaves, Antennas \& Propagation, vol. 3, no. 3, pp. 529-535, 2009.

[14] D. Upadhyay and R. P. Dwivedi, "Antenna miniaturization techniques for wireless applications," in Proceedings of the 11th International Conference on Wireless and Optical Communications Networks (WOCN '14), pp. 1-4, IEEE, Vijayawada, India, September 2014.

[15] A. M. A. Sabaawi, K. M. Quboa, and C. C. Tsimenidis, "Low profile UHF meandered antennas for RFID and WSN's applications," in Proceedings of the 10th Loughborough Antennas and Propagation Conference (LAPC '14), pp. 480-484, Loughborough, UK, November 2014.

[16] Y. Yao, J. Yu, and X. Chen, "Compact multi-band planar antenna design," in Proceedings of the Asia-Pacific Microwave Conference (APMC '12), pp. 1328-1330, Kaohsiung, Taiwan, December 2012.

[17] W. Di, S. Cheung, T. Yuk, and L. Liu, "Design of a printed multiband MIMO antenna," in Proceedings of the 7th European Conference on Antennas and Propagation (EuCAP '13), pp. 2020-2023, Gothenburg, Sweden, April 2013.

[18] Y.-C. Yu and J.-H. Tarng, "A novel modified multiband planar inverted-F antenna," IEEE Antennas and Wireless Propagation Letters, vol. 8, pp. 189-192, 2009.

[19] D. Yu, W. L. Liu, and Z. H. Zhang, "Simple structure multiband patch antenna with three slots," in Proceedings of the International Conference on Microwave and Millimeter Wave Technology (ICMMT '12), pp. 1067-1069, IEEE, Shenzhen, China, May 2012.

[20] I. K. Jeong, J. C. Young, and I. C. Jae, "Printed multiband terminal antenna for multiple wireless services," in Proceedings of the 12th International Conference on Antennas and Propagation (ICAP '03), vol. 1, pp. 324-327, Exeter, UK, March 2003.

[21] U. Nagar, S. Nagar, and R. S. Meena, "Dual band microstrip-fed antenna with parasitic patch for mobile applications," in Proceedings of the 5th International Conference on Computational Intelligence and Communication Networks (CICN '13), pp. 6-9, Mathura, India, September 2013.

[22] S. Shi, W. Che, W. Yang, and Q. Xue, "Miniaturized patch antenna with enhanced bandwidth based on signal-interference feed," IEEE Antennas and Wireless Propagation Letters, vol. 14, pp. 281-284, 2015. 

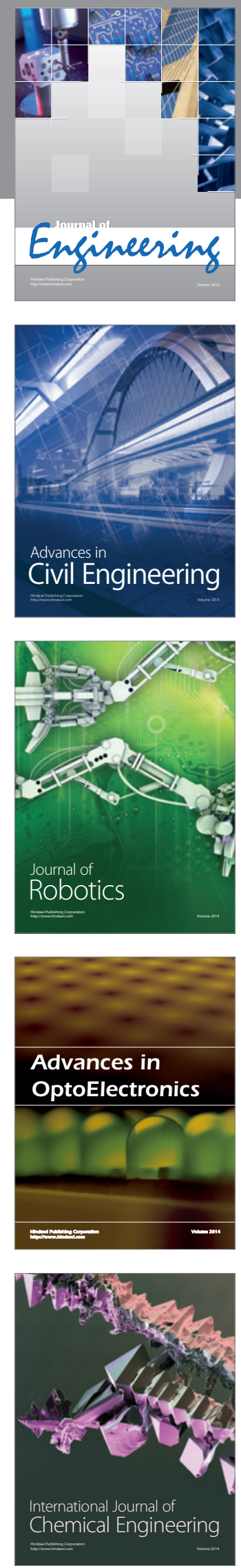

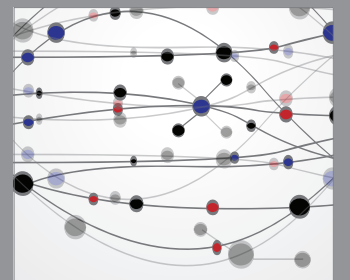

The Scientific World Journal
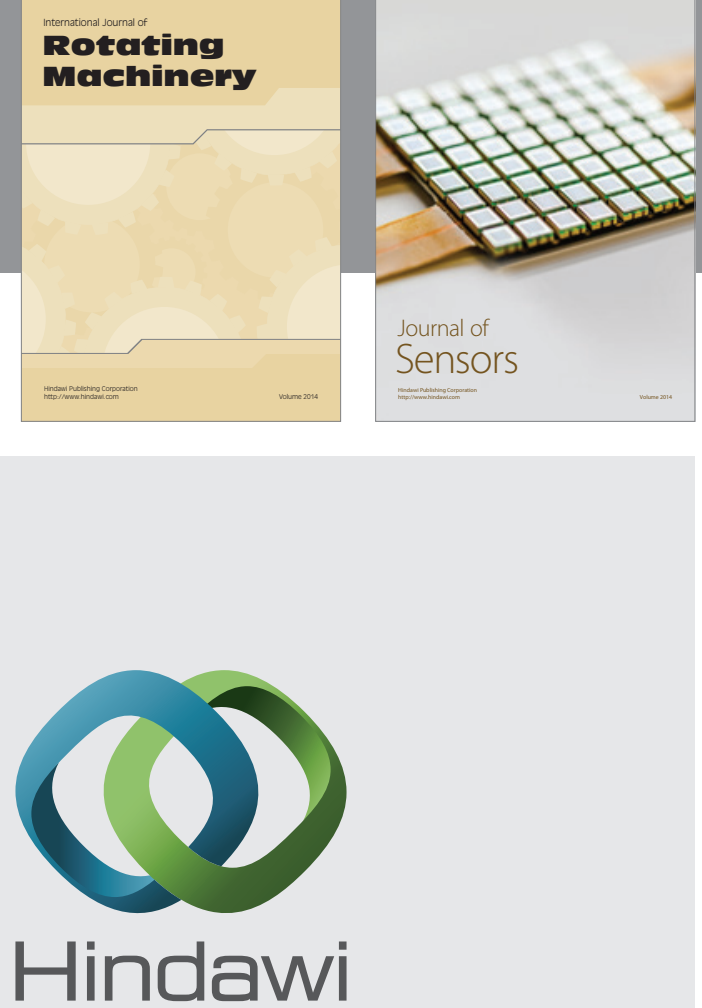

Submit your manuscripts at http://www.hindawi.com
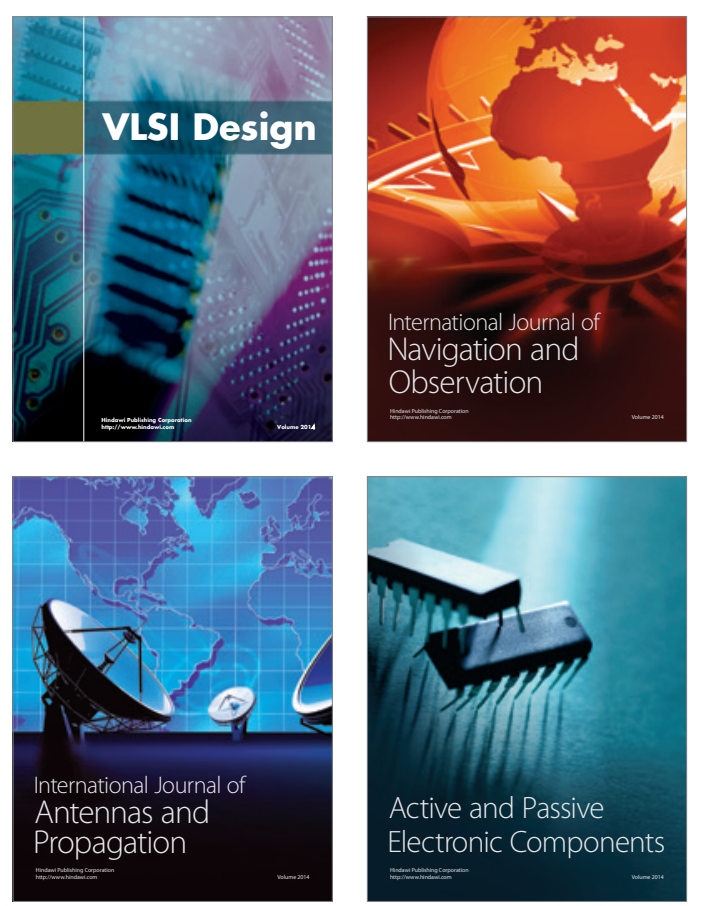
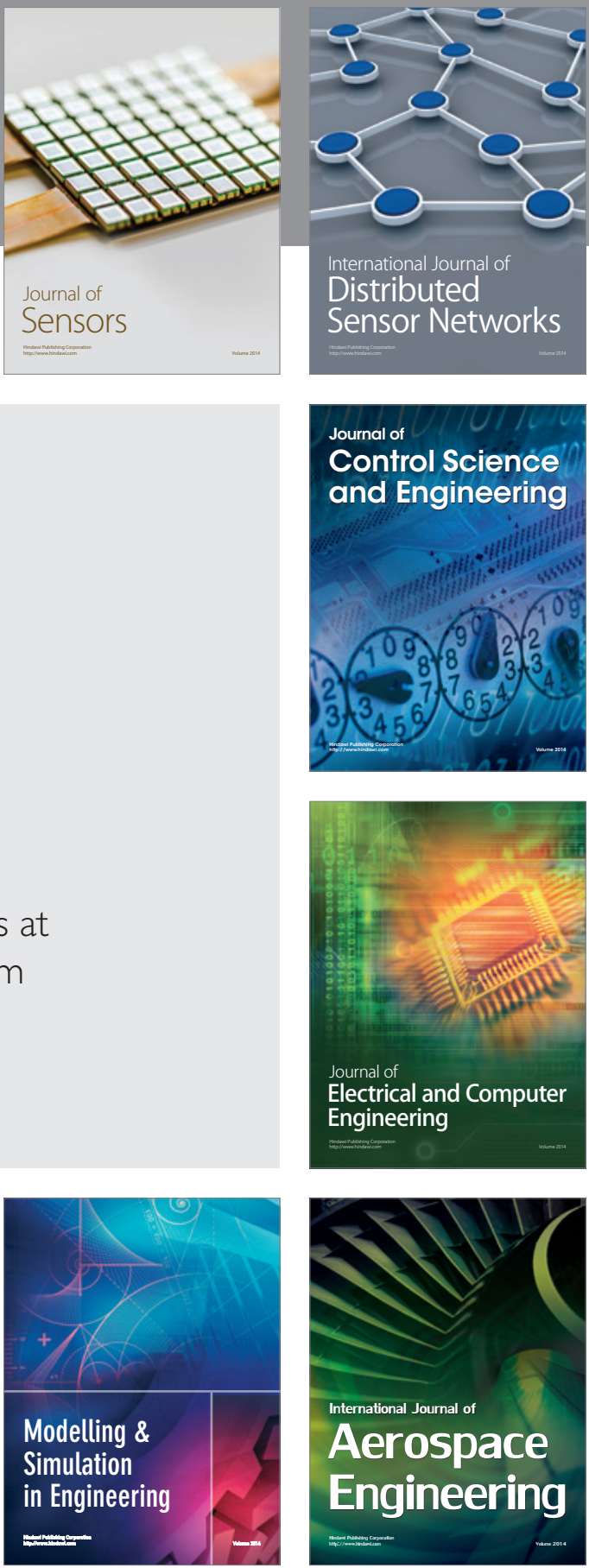

Journal of

Control Science

and Engineering
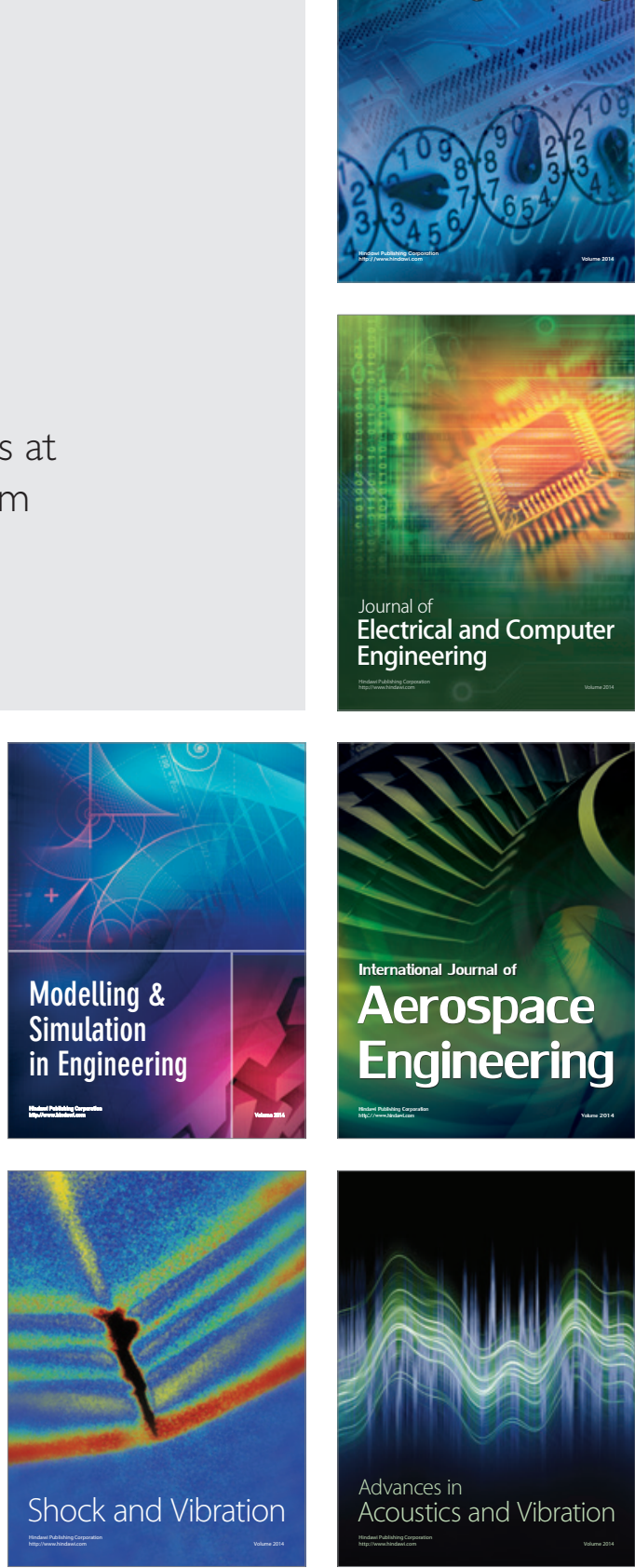